\title{
Bereaved parents' experiences of being informed about autopsy findings after the sudden and unexpected loss of an infant or small child
}

\author{
Anita Fjærestad, PsyD ${ }^{1 *}$ and Pål Kristensen, Ph.D²
}

${ }^{1}$ Center for crisis psychology, UiB, Møllendalsbakken 9, 5009 Bergen, Norway

${ }^{2}$ Center for crisis psychology, UiB, Møllendalsbakken 9, 5009 Bergen, Norway

*Corresponding author anita.fjaerestad@uib.no

\begin{abstract}
:
Background: Following the sudden and unexpected loss of an infant or small child, the police usually request a forensic autopsy National guidelines exist for how the autopsy report should be made available for the bereaved parents, but there is limited knowledge whether the guidelines are followed. This study aims to explore bereaved parents' experiences of being informed about autopsy findings.

Methodology: As part of in-depth follow-up interviews at 13 months post-loss, $\mathbf{2 4}$ couples were asked how they experienced being informed about autopsy findings. Participants' responses underwent thematic analysis.

Results: The results show that the waiting period before the autopsy report was made available was a burden for many parents, particularly those who experienced a delay in the process. Two main themes related to parents' experiences of being informed when the report was available: 'informed in a supportive and caring way' and 'difficult or negative experiences'.

Conclusion: Several factors are described that help parents cope with being informed about autopsy findings, such as: being informed according to the given timeframe by competent health personnel, face-to-face meetings at the hospital, being able to ask questions and routine follow-up contact. These factors are mostly described in the national guidelines. This study shows that when guidelines were followed, the majority of parents were satisfied with how they were informed. Unfortunately, some parents had negative experiences. Regular training and continuing education for health personnel are recommended.
\end{abstract}

Keywords:

SIDS, autopsy report, parents' experience, bereavement, grief

\section{INTRODUCTION}

In Norway, approximately 35 children aged 0-4 die suddenly and unexpectedly every year [1, 2]. Among these, 10-15 cases are unexplained and diagnosed with sudden infant death syndrome (SIDS) [1, 2]. When a child dies from unnatural causes, the death must be reported to the police, and the police usually request a forensic autopsy [3, 4]. The forensic autopsy is conducted when the cause of death is unknown or there is reason to investigate whether a criminal act has occurred [1]. The main objective for professionals conducting the autopsy is to investigate the cause of death and determine how the child died [1].

Losing a child is considered one of the most challenging incidents one can face [5]. Studies have shown that parents who have lost a child are, compared to other types of loss, especially at risk of developing complicated grief reactions and other mental and physical health problems $[6,7,8]$. Even a significant increase in mortality is reported $[9,10]$.

The sudden and unexpected loss of a child often also leads to self-blame and feelings of guilt [11], and bereaved parents often engage in rumination and counterfactual thinking (e.g. if I had done something differently my child would still be alive) after the death [12]. Subsequently, parents have a huge need for factual information in order to understand why their child died [11]. Many parents who lose a child to SIDS feel that information from the forensic autopsy is helpful in their grieving process, mainly because it provides them with an explanation of what happened to their child $[6,13]$. The autopsy may also reveal other information that is beneficial for parents, such as what did not cause the death, which can reduce ruminations, feelings of guilt and self-blame among parents [14]. But receiving information can also be a doble-edged sword. While the cause of death is unknown in SIDS, and parents are relieved to hear that they could not have prevented the death, others may unwittingly have contributed to increase the risk of death, for example through bed sharing, overheated bedrooms, smoking etc. [11].

Parents are usually notified by doctors at the hospital and given written information about how, when, and why the autopsy is conducted. The information also states that the final autopsy report will be available 4-6 months after the autopsy, and that parents will be invited for a meeting at the hospital to go through the report with medical personnel. The information given to parents at this stage is based upon national guidelines that were developed to help professionals inform parents about the final autopsy report [15]. The national guidelines also proclaim that health professionals 
must provide tailored information in a sensitive way, and that every hospital must guarantee that any personnel giving this kind of information are trained for it. More than one conversation is also recommended to ensure parents are able to consolidate the information and given more opportunities to ask questions [15]. While the national guidelines seem clear as to what they recommend, we have little knowledge to what extent they are followed.

\section{The current study}

The current study's main aim is to explore bereaved parents experiences of being informed about the autopsy report's findings after the sudden and unexpected loss of their infant or child.

\section{METHOD}

The study, which was conducted from 2013-2016, utilises a mixed-methods approach to examine parents' experiences when participating in death scene investigations (DSI) in Norway. Both quantitative and qualitative data were collected at six weeks and 13 months post loss. The current study is based on the follow-up in-depth interviews with $\mathbf{2 4}$ couples via telephone by the second author 13 months post loss.

We used qualitative methods as they can provide new information and uncover beliefs, thoughts, and motivations within individuals. A qualitative approach can also elaborate on complex questions where the aim is to gain an understanding of how individuals describe their experience of a given circumstance [16]. In-depth interviews provide the opportunity to both verify and elaborate on data from other sources, e.g. questionnaires [17].

\section{Sample and procedure}

Parents that accepted the DSI were asked to participate in the study by the team that conducted the DSI. If parents gave their written consent, this information was sent to the principal researcher of the study (second author). The researcher sent parents an information letter about the study and that they would be contacted for an interview 4-6 weeks after the death. At the end of the interview, they were asked if they could be re-contacted within a year for a potential follow-up interview.

\section{Material}

An interview guide was developed, which consisted of three parts: 1) facts about the feedback of the autopsy report (have they gotten feedback, who initiated the feedback, what was the final cause of death, etc.); 2) how they experienced the feedback/how useful it was; and 3) parents' suggestions of what could have been done differently. The interviews were conducted by telephone and lasted from 20-45 minutes. They were audiotaped and later transcribed verbatim.

\section{Data analysis}

The interviews were analysed through qualitative thematic analysis [18] This method allows us to identify, analyse and report patterns of meaningful units across data. Thematic analysis consists of different phases where the aim is to find meaningful units of data that can answer something about the research question. In this process we went through the data material several times and recognised patterns of meaningful units [18]. All meaningful units related to how parents experienced acquiring information about the final autopsy report were identified in the interviews which were read and re-read several times. Statements with similar content were coded and named using QSR International's NVivo 12 software [19], before being categorised into main- and subthemes.

\section{Ethical considerations}

Participation in this study relied on written, informed consent, which was collected from parents beforehand. They were provided with information on the background and purpose of the study and informed that they could at any time --without giving a reason-- withdraw their participation. All written, oral (audio tapes) and personal information is anonymised in this paper.

The interviews were conducted by an experienced grief researcher and psychologist (second author) to ensure that the parents were approached in a sensitive and respectful way. They were given open-ended questions where they could speak freely about their experience. It was emphasised that they could take their time and pause for breaks if needed. The interviewer was sensitive to difficult topics and adjusted the interview accordingly.

The study was approved by the Regional Committees for Medical and Health Research Ethics (REK Vest).

\section{RESULTS}

During the project period, parents of 42 children that died consented to participate in a DSI. Parents of $\mathbf{3 1}$ of these children were interviewed in the first data collection (70\%). Of the 11 couples that did not participate in the first data collection, four were non-native and did neither speak Norwegian nor English, six couples refused to participate due to the strain of their loss, and for one couple the reason was unknown. All 31 couples that participated in the first data collection initially agreed to be contacted for a follow-up interview. 24 of these couples participated in the follow-up and we have no information as to why seven couples did not. Parents from all regions of Norway took part in the study, with the majority living in eastern parts of Norway. We have no information on whether or not non-participants rated the DSI or the information process regarding the autopsy findings more or less positively than the participants. Of the $\mathbf{2 4}$ children of parents that were included in the follow-up, 18 were diagnosed SIDS and in the last six cases the cause of death was acute illness.

We divided the information process into two parts: how parents experienced waiting for the autopsy report to be made available, and how they experienced the meeting itself where they were informed about the autopsy findings.

\section{Waiting for the autopsy report}

Almost all parents reported that waiting for the final autopsy report was difficult. They dreaded both the meeting and returning to the hospital where their deceased child was brought in. The interviews revealed that this waiting period was extended for a significant number of parents, which made coping even more difficult. In total, 11/24 of the couples were 
informed according to the national guidelines, 4-6 months after their loss. For $7 / 24$ it took almost a full year, and $3 / 24$ waited over a year. The remaining three couples had not been informed at all 13 months after their loss.

When the autopsy report was made available, the information was shared by different sources. 13/24 were invited to the hospital ward where their deceased child first was brought in. 6/24 received information from the police, while $2 / 24$ heard directly from the forensic pathologist. While the majority of parents were informed face-to-face, five couples learned of the findings via telephone, mainly from the police, but also in some cases from the hospital.

Being informed about the results of the final autopsy report was described by parents as an important piece in the final puzzle and as a kind of a closure regarding the cause of death. One parent said:

One cannot get closure... maybe that's the wrong word but it became very difficult to move on before that final piece of the puzzle was in place.

Many parents had ruminated about why it took so long and why they did not hear anything from the hospital. Not knowing what happened made room for speculations that were worse than the reality, specifically about whether they were to blame for the death and if they should have handled the situation before their child died differently. They were anxious and scared of what the result of the report would be. One couple said:

We were dreading the meeting and we were hoping to just be done with it. It was very frustrating to wait. We did not know the cause of death (...). We were scared of what they were going to say.

Many of the parents had called the hospital to remind them that they were waiting for the autopsy results, because it seemed like they would not get the information if they did not reach out. As one mother said:

We called the hospital when we did not hear from them. We called a lot. We asked why it took so long because they initially told us it would be 3-4 months or so.

Some were not able to do this, either because they were scared of what might come of it or because they did not have the energy. One father said:

I often think that I should have sent them an e-mail. I have written it, but I have been afraid to send it because I was afraid they had reached a different conclusion and that I was to blame after all.

None of the parents received any explanation of why it took so long for the autopsy to be completed. One couple said:

It has been totally silent. Nobody has been in touch with us after that day (the death scene investigation). We tried to call our contact at the hospital.

\section{Being informed of the final autopsy report}

We identified two main themes that described how the parents experienced being informed of the autopsy findings: informed in a supportive and caring way and difficult or negative experiences. Both are further divided into subthemes.

Informed in a supportive and caring way

For this main theme, the following sub-themes were identified: informed faceto-face, being met with respect and empathy and informed in a sensitive way.

\section{Informed face-to-face}

The way the information meeting was organised was considered important by the majority of parents. First of all, parents valued encountering a proactive health care service. They did not feel the need to reach out or try to contact anyone to get information from the autopsy report. One mother said:

The doctor that met us the morning we brought our child in, she called me and said the final autopsy report was ready and that she would invite us for a final meeting at the hospital to go through it. I think it was good to get some answers and they also had some details that we did not know from before.

Furthermore, meeting health professionals face-to-face was important, in particular meeting the same doctor or nurse that had been there the first time they arrived at the hospital. This made the situation predictable and safe. They felt that the doctor had first-hand knowledge of their case and could more easily answer questions they might have about the report, which was essential. As one mother said: "They answered all my questions. It seemed like they had everything under control.

\section{Being met with respect and empathy}

The parents also emphasised the importance of being met in a respectful manner. The majority experienced that the doctor/nurse was understanding and showed compassion and empathy throughout the meeting. One mother said:

They were very understanding, helpful and respectful. They even advised me regarding what I should do because I did not agree with the cause of death.

Parents also noted the importance of having set aside enough time in the meeting to allow for all their questions to be answered and elaborated on if needed. One mother reported:"I felt they made time for us and they let us ask any questions we needed. It was a good experience for us". Overall, the attitude and behaviour of the doctor or nurse reassured parents and made them feel they were taken seriously.

\section{Informed in a sensitive way}

Several parents emphasised that the way the doctor/nurse had informed them was important. For example, some pointed out that they had been given informative explanations but not too much details about the autopsy. Thus, the information was given in an understanding and caring way. One couple said: 
We were being informed about what was happening at all times and got informative explanations. Everyone we met was competent and professional. They informed and explained. We are very happy with how everything was organised, although we wish this would never have happened in the first place.

The most difficult meeting occurred when parents were told that their actions, such as co-sleeping or overheating the room, had most likely contributed to the child's death. Giving such bad news, while at the same time taking care of the parents, demanded high skills from the health professionals. One mother experienced that even though this confirmed her worst nightmare, and had increased her feelings of guilt, she was pleased with the caring way the doctor and nurse handled the situation. She said:

They informed us in a caring way. When they informed us about the cause of death, the nurse first stated that this is not an easy thing to say. She said that the autopsy had concluded that the position he was found in suggested that co-sleeping could have contributed to his death. That was what I dreaded most to hear. But she explained so we could understand, she took several small breaks while she told us, and we did not feel that they blamed us for the death. They managed to take good care of us in the situation.

\section{DIFFICULT OR NEGATIVE EXPERIENCES}

For this main theme, the following two sub-themes were identified: left with unanswered questions and wrongful or withheld information.

\section{Left with unanswered questions}

Even though the parents were prepared, it was difficult to be told that their child had died of SIDS. For some it was as if they had been told:"we do not know why your child died". While it excluded some causes of death (i.e. suffocation), which was a relief, it also reinforced or cemented the meaninglessness of the death and blame. However, it also excluded the thought that they could have done something to prevent the death. One father said:

We did not really get any cause of death because they never found out what happened, which was frustrating, but at least they could tell us she did not suffocate.

Others were often left with unanswered questions when the information came from persons without health education, most notably from the police. Parents were largely unfamiliar with national guidelines which say that this type of meeting shall always involve medical doctors at the hospital. Furthermore, when information from the final autopsy report was given via telephone, parents felt unprepared and unable to think clearly about what to ask. One couple said:

The police called us to explain the report over the phone (...). This happened during our vacation. We were at a shopping mall and on the phone with them when they just began reciting what the report said. We were not prepared (...). After that we had so many questions, but this was during the summer, so we were not able to get in touch with any doctors to elaborate on what the police told us.

Another concern is that when parents were informed over phone, they did not receive the information together as a family. Consequently, parents who received the call had to inform others in the family, which was not neither preferable nor easy. This precludes the all-important emotional support that should be present when parents are together. One mother said:

I wish it would have been done differently because I was the only one who got this information. My husband got his information from me (...). We both should have been informed at the same time.

Even when meeting a doctor at the hospital, some parents felt that he/ she could not answer questions or elaborate on the findings due to lack of first-hand knowledge about their child. This was especially important when parents were told that having co-slept with the child was a possible cause of death. They would rather have spoken to the doctor they had met before or the forensic doctor that did the autopsy. One mother said:

The conclusion was sudden infant death syndrome, but they could not confirm that I did not suffocate her. The only thing I could ask them were questions about the report itself. I have asked for an appointment with the doctor that met us at the hospital the day she died. Maybe we can get some more information... Also, we want to talk to the forensic doctor who did the autopsy.

\section{Wrongful or withheld information}

Only a handful of parents had direct negative experiences during the meeting, and these resulted from, serious actions due to deviations from the national guidelines, or a lack of experience or incompetence. For example, some parents were given the wrong information about the cause of death. This was highly distressing, creating many ruminations and self-blame. One couple was told that their child had died of a disease, which later turned out to be nonsignificant symptoms concerning the cause of death. The parents went through an agonising period, since they ruminated about what they failed to see or notice in their child.

Since the police were unable to answer their questions, they were left alone with their difficult feelings until they were able to get in touch with a doctor at the hospital. As they described it:

They told us the report suggested our child had a lung infection (...). We were left wondering if the lung infection could be the cause of death and that we missed it. Three weeks went by where we were scared and thought our child had a lung infection that caused him to die without us noticing it.

Another negative experience was when the doctor at the hospital deliberately held back information that suggested that the parent's actions may have contributed to their child's death. This was interpreted positively by the parents as a way of protecting them from getting information about their contribution to the child's death, but it was also a question the mother already had in her mind before the meeting and one that she needed an answer to. The mother said: 


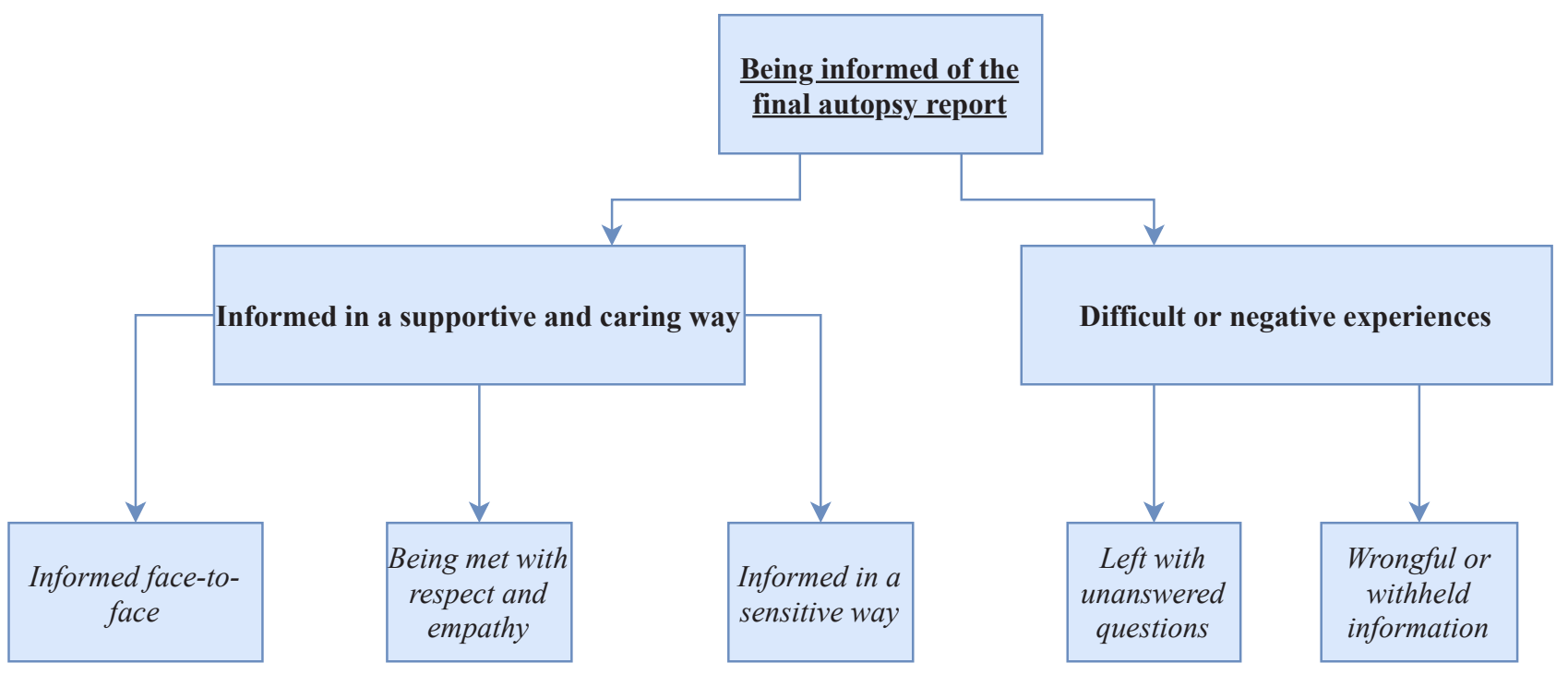

Figure 1:????

The doctors tried to spare us from the truth. They did not tell us the report said that us sharing a bed could have been the triggering cause. I got the impression they tried to spare us and that they were hoping that we would not ask about it.

\section{DISCUSSION}

This study explored bereaved parents' experiences of being informed about the autopsy findings after the sudden and unexpected loss of their child. We divided parents' experiences into those who felt supported during the information meeting, and those who had negative experiences [figure 1].

Generally, receiving information about the cause of death represents the first step towards accepting that the death has happened, and subsequently adapting to the loss [20]. Being informed about the final autopsy report represents a kind of closure for bereaved parents [21]. Earlier research has emphasised that parents should be able to receive information throughout the process and that they should be invited to receive information from the final autopsy report as soon as it is ready [22, 23, 24]. The current study confirms the importance of receiving this information on time, since waiting for the final report was distressing for many.

Receiving information from the autopsy has several important functions, such as clarifying any speculation about what has caused their child's death, potentially reducing parents' self-blame [25]. Still, the information process does not only consist of providing the "hard facts"; how these facts are provided is equally important.

In the current study, several factors differed between parents who felt supported during the information process and those who had more negative experiences. First of all, meeting the same doctor or nurse who was at the hospital the first time the parents came in with their child gave them some feeling of predictability and control in a situation over which they had much anxiety. Secondly, being met with empathy and understanding was crucial, particularly for those who received bad news, such as when co-sleeping had contributed to the child's death. In this situation it became obvious that parents who received direct information in a supportive way were more satisfied with the meeting. Having the time to ask questions and the possibility to react to the information was also part of what parents experienced as supportive, as was giving information in "small doses" and preparing parents for what was difficult for them to hear.

The factors identified as important for parents who felt supported during the information process are essentially in line with the national guidelines. When national guidelines were followed, parents reported being more satisfied. Nonetheless, the waiting period before the autopsy report was made available was a burden for many parents, particularly those who experienced a delay in the process. The guidelines lack information on how to inform parents about a potential delay and follow-up routines regarding the delay.

Some parents also had unfortunate experiences during the information meeting, for example when critical information about the cause of death was withheld. Withholding information is known to challenge bereaved parents trust in the health care system and increase anxiety in an already distressing situation [25]. Other examples of negative experiences are when parents are given wrongful information about the cause of death or when the person informing them was not able to answer important questions about the findings in the report. These unfortunate situations mostly occurred when information was given by persons without specific competency or health education, such as the police. Giving information over the telephone also compromised parents need for support in this sensitive situation. Overall, this shows that the information process involves telling the facts, but also that it needs to be done in a way that builds trust and confidence in the conclusions conveyed.

\section{LIMITATIONS}

This study has some limitations. Firstly, the participants were interviewed thirteen months after their loss and other experiences in their life could be conflicting with their memory. In addition, the process of analysing 
Informing bereaved parents about the findings from the autopsy

Recommendations

- Outreaching contact

- Competent health personnel

- Following the given timeframe

- Face-to-face meetings

- Direct communication

- Being sensitive and supportive

- Routine follow-up contact

- Regular practice and training

Figure 2: ????

qualitative data could lead to different themes and conclusions based on who conducts the analysis. Furthermore, the participants in this study were interviewed via telephone and therefore one should expect some information to become lost or misinterpreted. Finally, we lack information about the parents who chose not to participate in the study. We have to take into consideration that those parents who did not participate in our study may have been more dissatisfied with the way they were informed about the autopsy.

\section{IMPLICATIONS}

This study suggests that there are certain factors that make the information process easier for the parents to cope with [figure 2]. Information from the final autopsy report should be given face-to-face and in a direct but supportive way by competent health professionals. Routine followup contact should be prioritised to make sure parents are not left with unanswered questions $[22,23,24]$, especially regarding vulnerable parents where, for example, co-sleeping may have contributed to the child's death. Health professionals should reach out to the parents as soon as the report is ready. When parents are given a timeframe for when the final autopsy report should be ready, this timeframe should be upheld. If not, they should be informed about the delay. Furthermore, it is important that the findings in the report are given face-to-face at the hospital where the child was first brought in and not over the telephone. The health professionals informing the parents should preferably be a doctor or a nurse they have met before and someone capable and competent enough to answer any questions they might have. Professionals involved in this process in the future should be aware of how different approaches to providing information from the final autopsy report can affect the outcome for bereaved parents.

\section{CONCLUSION}

Although the majority of the parents were satisfied with the information process when it was conducted according to national guidelines, we also found that the guidelines were not followed in all cases. When guidelines were not followed, parents reported having more negative experiences. Even if the guidelines were followed, parents reported difficult experiences when they had to wait longer than the expected 4-6 months to receive information about autopsy findings. If guidelines were to be revised, we recommend that they include a point to inform parents and keep them up to date when there is a delay in the process. Regular training and continuing education for health personnel carrying out this task are also recommended to ensure bereaved parents feel well taken care of.

\section{REFERENCES}

[1] Rognum, T.O., Bøylestad, L., Dødstedsundersøkelse - helsehjelp ved plutselig og uventet barnedød, 2015

[2] Kristensen, P., Undersøkelse av dødsstedet ved plutselig og uventet barnedød. En evalueringsstudie, Nasjonalt Kunnskapssenter om Vold og Traumatisk Stress, 2018

[3] Helse- og omsorgsdepartementet, Forskrift om leges melding til politiet om unaturlig dødsfall o.l. (FOR-2000-12-21-1378), 2001, https://lovdata.no/dokument/ SF/ forskrift/2000-12-21-1378?q=FOR-2000-12-21-1378

[4] Justis-og beredskapsdepartementet, Forskrift om ordningen av påtalemyndigheten (FOR-1985-06-28-1679), 1986, https://lovdata.no/dokument/SF/forskrift/1985-06281679?q=FOR-1985-06-28

[5] Goldstein, R.D., Parental grief, In: Duncan J.R., Byard, R.W. (Eds.), SIDS Sudden infant and early childhood death: The past, the present and the future, University of Adelaide Press, Adelaide, 2018
[6] Dyregrov, A., Dyregrov, K., Long-term impact of sudden infant death: a 12- to 15year follow-up. Death Studies, 1999, 23(7), 635-661, doi:10.1080/074811899200812

[7] Stroebe, M., Schut, H., Stroebe, W., Health outcomes of bereavement, Lancet, 2007, 370, 1960-1973, doi:10.1016/S0140-6736(07)61816-9

[8] Kristensen, P., Dyregrov, K., Dyregrov, A., Hva skiller forlenget sorg-forstyrrelse fra depresjon?, 2017, 7-8, 137, 539-9

[9] Morris, S., Fletcher, K., Goldstein, R., The grief of parents after death of a young child, Journal of Clinical Psychology in Medical Settings, 2018, 26(3), 321-338, doi: 10.1007/s10880-018-9590-7

[10] Wilcox, H.C., Mittendorfer-Rutz, E., Kjeldgård, L., Alexanderson, K., Runeson, B., Functional impairment due to bereavement after the death of adolescent or young adult offspring in national population study of 1,051,515 parents, Soc Psychiatry Psychiatri Epidemiol, 2015, 50(8), 1249-56, doi: 1007/s00127-014-0997-7 
[11] Garstang, J., Griffiths, F., Sidebotham, P., Parental understanding and self-blame following sudden infant death: a mixed-methods study of bereaved parents' and professionals' experiences, BMJ Open, 2016, 6, e011323, doi: 10.1136/bmjopen2016-011323

[12] Gold, K.J., Sen, A., Leon, I., Whose fault is it anyway? Guilt, blame and death attribution by mothers after stillbirth or infant death, Illness, Crisis \& Loss, 2018, 26(1), 40-57

[13] Sullivan, J., Monagle, P., Bereaved parents' perceptions of the autopsy examination of their child, Pediatrics, 2011, 127(4), doi: 10.1542/peds.2009-2027

[14] Heltne, U., Dyregrov, A., Dyregrov, K., Death scene investigation: parents' experiences, Scandinavian journal of Forensic Science, 2016, 22(2), 57-63, doi: 10.1515/sjfs-2016-0009

[15] Helsedirektoratet, Veileder for informasjon til pårørende $\mathrm{i}$ forbindelse med obduksjon og forskning ved dødsfall hos barn, IS-2237, Oslo, 2016

[16] Smith, J.A., Qualitative psychology: A practical guide to research methods, 3rd ed., SAGE Publications, London, 2015

[17] Creswell, J.W., Zhang, W., The application of mixed methods designs to trauma research, Journal of Traumatic Stress, 2009, 22(6), 612-621, doi: 10.1002/jts.20479

[18] Braun, V., Clarke, V., Using thematic analysis in psychology, Qualitative research in psychology, 2006, 3(2), 77-101, doi: 10.1191/1478088706qp063oa

[19] NVivo qualitative data analysis software; QSR International Pty Ltd. Version 12, 2018
[20] Dyregrov, A., Regel, S., 2012, Early interventions following exposure to traumatic events: Implications for practice from recent research, Journal of Loss and Trauma, 2012, 17, 271-291, doi: https://doi.org/10.1080/15325024.2011.616832

[21] Dyregrov, A., Kristensen, P., Information to bereaved families following catastrophic losses. Why is it important?, 2020, Journal of Loss and Trauma, doi: https://doi.org/1 0.1080/15325024.2019.1710954

[22] Fleming, P., Blair, P.S., Sidebotham, P.D., Hayler, T., Investigating sudden unexpected deaths in infancy and childhood and caring for bereaved families: an integrated multiagency approach, BMJ, 2004, 328-331.doi: https://doi.org/10.1136/ bmj.328.7435.331

[23] Howatson, A.G., The autopsy for sudden unexpected death in infancy, Current Diagnostic Pathology, 2006, 12(3), 173-183, doi: https://doi.org/10.1016/j. cdip.2006.03.008

[24] Garstang, J., Griffiths, F., Sidebotham, P., Rigour and rapport: a qualitative study of parents' and professionals' experiences of joint agency infant death investigation, BMC Pediatrics, 2017, 17(48), doi: 10.1186/s12887-017-0803-2

[25] Garstang, J., Griffiths, F., Sidebotham, P., What do bereaved parents want from professionals after sudden death of their child: a systematic review of the literature, BMC Pediatrics, 2014, 14(269), 1471-2431, doi: https://doi.org/10.1186/1471-2431$14-269$ 